\title{
Observed winter Alpine precipitation variability and links with large-scale circulation patterns
}

\author{
R. Quadrelli*, M. Lazzeri, C. Cacciamani**, S. Tibaldi \\ Agenzia Regionale Prevenzione ed Ambiente - Servizio Meteorologico Regionale, Viale Silvani 6, 40122 Bologna, Italy
}

\begin{abstract}
The winter precipitation variability over the Alpine region is described by a standard principal component analysis (PCA), performed starting from monthly precipitation anomalies for the 1971-1992 winters. With respect to the temporal variability, significant trends are found over some areas within the domain. In particular, the Alpine orography signature enables identification of 2 major sectors, located north and south of the chain, which exhibit an increase and a more significant decrease, respectively, in precipitation during the period examined. The relationship between surface and upper air data is then investigated by means of covariance maps of the precipitation principal components (PCs) with the $500 \mathrm{hPa}$ geopotential height monthly anomalies and also by studying the correlation between the same PCs and some indices of large-scale circulation patterns, such as the North Atlantic Oscillation (NAO) and the Northern Hemisphere blocking frequency. The 2 leading precipitation patterns are characterized by significant relationships with large-scale anomalies: the NAO explains most of the Alpine precipitation variance, and a strong link is also found with Euro-Atlantic blocking. No significant connection is found between winter Alpine precipitation variability and the El Niño signature as deduced by sea-surface temperature anomalies.
\end{abstract}

KEY WORDS: Alpine precipitation $\cdot$ Large-scale circulation $\cdot$ Interannual variability $\cdot$ Trends

\section{INTRODUCTION}

Precipitation is one of the most important meteoclimatic parameters, because of its strong impact both on natural ecosystems and human society. Characterized by a high spatial variability, it is generally determined by a large number of factors developing on different spatial scales. One of the most important forcing elements is orography, which interacts strongly with the large-scale flow, contributing to the determination of the precipitation field structure (Houze 1993). This interaction is very active in the Alpine region, due to the location of the chain in the transition region between the Atlantic Ocean, the Mediterranean Sea and the European continent (Schär et al.

\footnotetext{
${ }^{*}$ Present address: Dept of Atmospheric Sciences, University of Washington, Box 351640, Seattle, Washington 981951640, USA

${ }^{* *}$ Corresponding author. E-mail: c.cacciamani@smr.arpa.emr.it
}

1998). Associated effects include, for example, the genesis of sub-synoptic orographic cyclones in the Gulf of Genoa (Buzzi \& Tibaldi 1978, Tibaldi et al. 1990) and the modification of cold fronts after their passage over the Alpine chain from the north-west. Even smaller circulation features can be triggered by the Alpine orography, such as 'multicell' and 'supercell' thunderstorms (Cacciamani et al. 1995).

All these factors lead to highly complex spatial variability of the precipitation over the Alpine region (Cacciamani et al. 1994, Widmann 1996). Most of the old climatological studies (see Fliri 1975 for an overview) were unable to capture this high variability due to the lack of an adequate observation network, coverage being essentially based on only Global Telecommunication System (GTS) data. Recently a much improved precipitation climatology over the Alpine region has been produced by Frei \& Schär (1998), who used a large number of non-GTS rain-gauges made available by different institutions operating in the area. Starting from this large volume of raw data, daily

(C) Inter-Research 2001 
precipitation analyses were created, leading to a much better definition of the Alpine mesoscale precipitation climatology.

A complete physical understanding of the Alpine region climate can only be obtained by studying the links between interacting processes on different time and spatial scales. The relationship between largescale anomalies and local weather can be investigated using several statistical techniques. For example singular value decomposition (SVD) and canonical correlation analysis (CCA) can be performed between the local weather parameters (e.g. precipitation) and the upper air large-scale meteorological fields; alternatively, principal component analysis (PCA) applied to one field can be followed by the computation of composite or correlation maps with other fields (see Wallace et al. 1992 or Bretherton et al. 1992 for a comparison of these methods).

The study of the connection between local weather and large-scale atmospheric circulation patterns (ACPs) is also a prerequisite to the 'downscaling' of GCM output (Giorgi \& Mearns 1991).

In this context we focus our attention on the Alpine area, analyzing the winter precipitation variability for the period 1971-1992, and trying to illustrate how it is related to the larger scale synoptic circulation. Significant relationships are found between the spatial variability over the region and larger-scale circulation patterns, such as the North Atlantic Oscillation (NAO) and blocking in the European and Atlantic sectors.

The paper is organized as follows: the data sets and diagnostic tools used are described in Section 2; Section 3 is devoted to the discussion of spatial and temporal variability of Alpine precipitation; in Section 4 we describe the links between precipitation in the Alpine region and larger-scale circulation anomalies; and finally in Section 5 we give the conclusions of the study.

\section{DATA AND DIAGNOSTIC TOOLS USED}

The precipitation data sets used in this study are taken from Xie \& Arkin (1997) and Frei \& Schär (1998), while upper air $500 \mathrm{hPa}$ geopotential height (Z500) and sea-level pressure (SLP) fields are taken from the operational reanalysis (Kalnay et al. 1996) of the National Centers for Environmental Prediction (NCEP). The Frei \& Schär precipitation data set consists of highresolution daily data on a $0.22^{\circ} \times 0.3^{\circ}$ lat-lon grid, for the period 1971-1995 over the Alpine region, which extends from 42.18 to $49.88^{\circ} \mathrm{N}$ and from 2.1 to $18.9^{\circ} \mathrm{E}$. The Xie \& Arkin precipitation data are global and include monthly mean precipitation fields on a regular $2.5^{\circ} \times 2.5^{\circ}$ grid for $1979-1995$. The NCEP reanalysis data set covers $40 \mathrm{yr}$ (1957-1996), and it includes 4 values each day for several variables on a $2.5^{\circ} \times 2.5^{\circ}$ regular grid. In this work we present results obtained both from daily and monthly averages of $Z 500$.

In addition, some major indices have been used to describe well-known large-scale patterns: the NAO, the 'Niño 3', the Pacific North American pattern (PNA) and the Atlantic and European blocking indices. The NAO index is calculated following the definition given by Hurrell (1995), based on the difference of normalized monthly SLP between Lisbon, Portugal, and Stykkisholmur/Reykjavik, Iceland. The 'Niño 3' index, obtained from the Global Sea Ice and Sea Surface Temperature (GISST) data set (Parker et al. 1995), is defined as the average of the monthly mean seasurface temperatures (SSTs) over the area from 150 to $90^{\circ} \mathrm{W}$ and from $5.6^{\circ} \mathrm{S}$ to $5.6^{\circ} \mathrm{N}$. The PNA index is calculated from monthly mean Z500 data, following the definition of Wallace \& Gutzler (1981), as a linear combination of the normalized height anomalies at the 4 pattern centers. The monthly blocking frequency is computed starting from daily Z500 data and using the Tibaldi \& Molteni (1990) index, which detects for each longitude the frequency of occurrence of blocking events (easterly geostrophic winds at least at 1 latitude between 40 and $60^{\circ} \mathrm{N}$ and westerly geostrophic winds larger than $5 \mathrm{~m} \mathrm{~s}^{-1}$ at least at 1 latitude north of $60^{\circ} \mathrm{N}$ ). The European blocking index is obtained as an average of the longitudes included between $20^{\circ} \mathrm{W}$ and $40^{\circ} \mathrm{E}$, while for the Atlantic index we used the area between 80 and $20^{\circ} \mathrm{W}$, as defined in Pavan et al. (2000).

We investigated winter precipitation variability over the Alpine area by performing a standard PCA based on the covariance matrix of the monthly anomalies, evaluated with respect to monthly climatology, for the 22 yr period 1971-1992.

The physical significance of the leading patterns is assessed by the use of a Monte Carlo test at the $99 \%$ significance level. This selection rule is based on a comparison between the fractions of variance explained by the empirical orthogonal functions (EOF) of respective order computed for the analyzed field and for a fictitious random field (Overland \& Preisendorfer 1982). It consists of an EOF decomposition repeated on 100 randomly generated data sets of the same size as the real one. The eigenvalues of respective order of all the 100 decompositions are sorted into ascending magnitude, and the 99th is taken to represent the variance explained by each given EOF of the random field. For each of the leading 3 precipitation EOFs described in the next section, the associated eigenvalue is much greater than its corresponding one in the random field EOF decomposition.

The choice of the winter months (December-March) is motivated by the greater spatial coherence of pre- 
Fig. 1. Orography of the Alpine region (m)
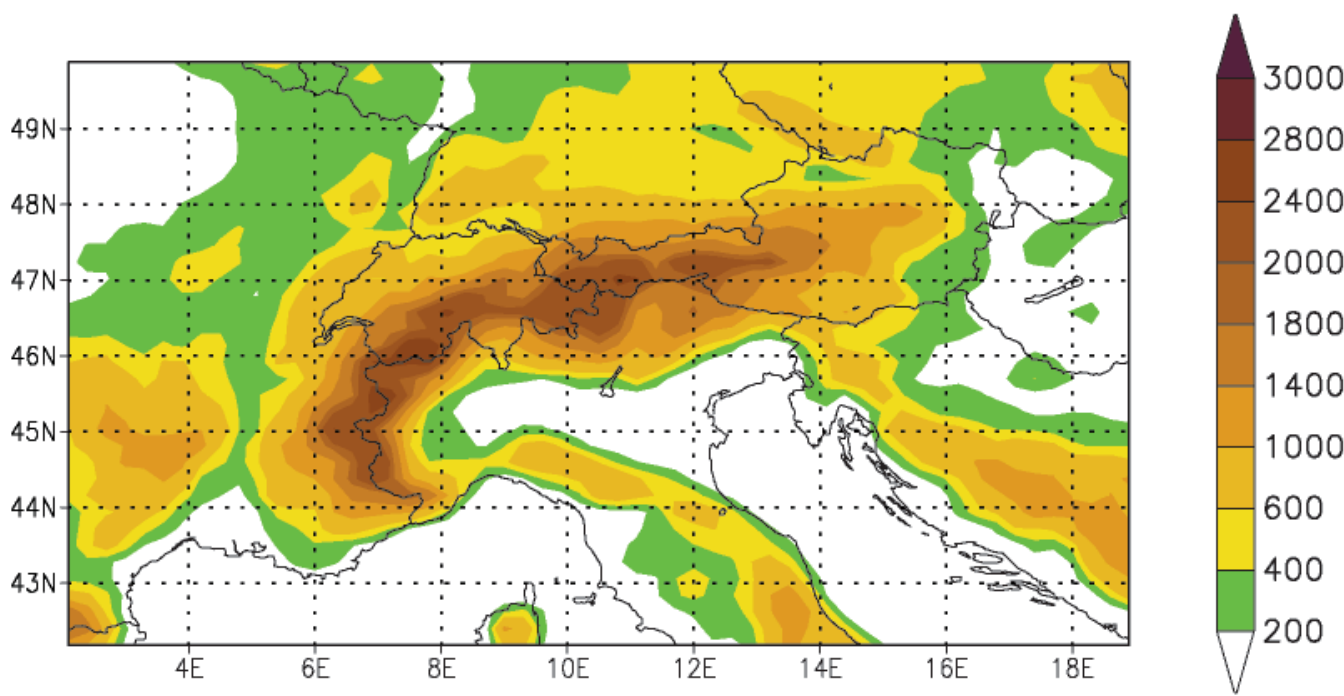

Fig. 3 shows the leading 3 precipitation EOFs, computed from the winter monthly anomalies. They explain respectively $38.6,21.3$ and $7.8 \%$ of the total variance over the Alpine region for 1971-1992. The spatial structure of EOF1, similar to the described winter mean field (see Fig. 2), is characterized by positive values over the whole area, with a strong orographic signature. This similarity of EOF1 with the mean field reflects the fact that the variance turns out to be maximal when the mean field is larger, as expected for precipitation. The second EOF shows a dipolar structure, with positive and negative sectors over the northern and southern sides, respectively, of the Alpine chain. An east-west variability over the region, with a particularly strong signal over the Ticino area (at the boundary between southern Switzerland and Italy, around $9^{\circ} \mathrm{E}, 46^{\circ} \mathrm{N}$ ), is explained by the third EOF, while the fourth (not shown) captures more localized signals, which can be described as 2 opposite anomalies over the southern Massif Central and northeastern Italy.
Fig. 2. Mean precipitation over the Alpine region for the winter months (December-March) 1971-1992 (mm d $\left.{ }^{-1}\right)$

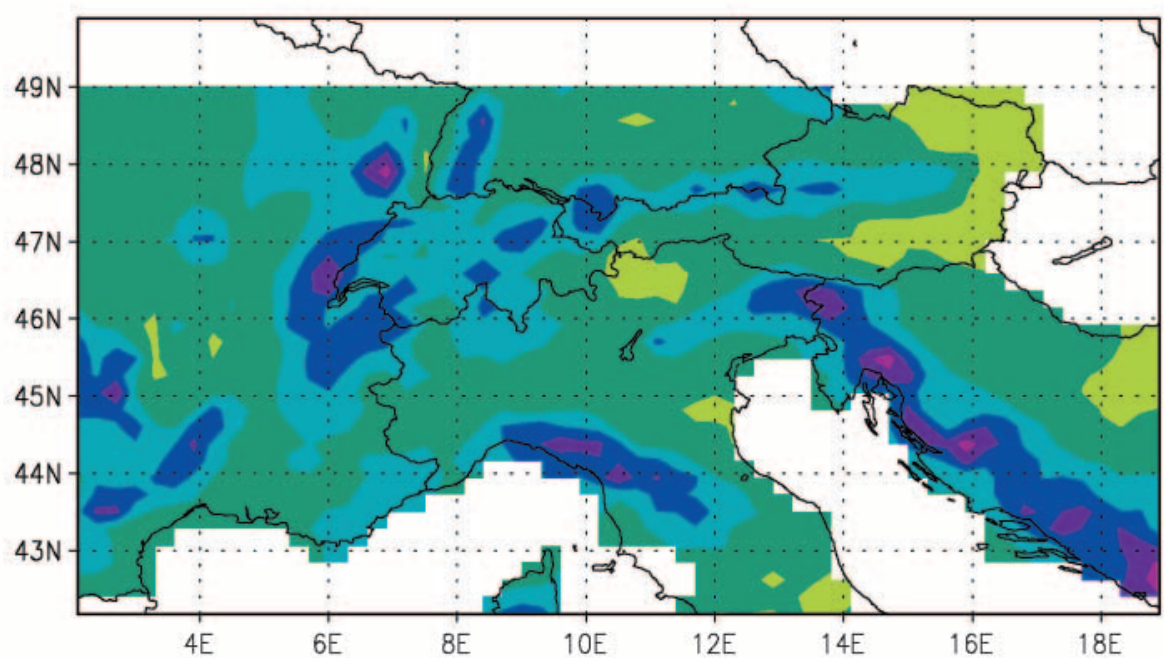



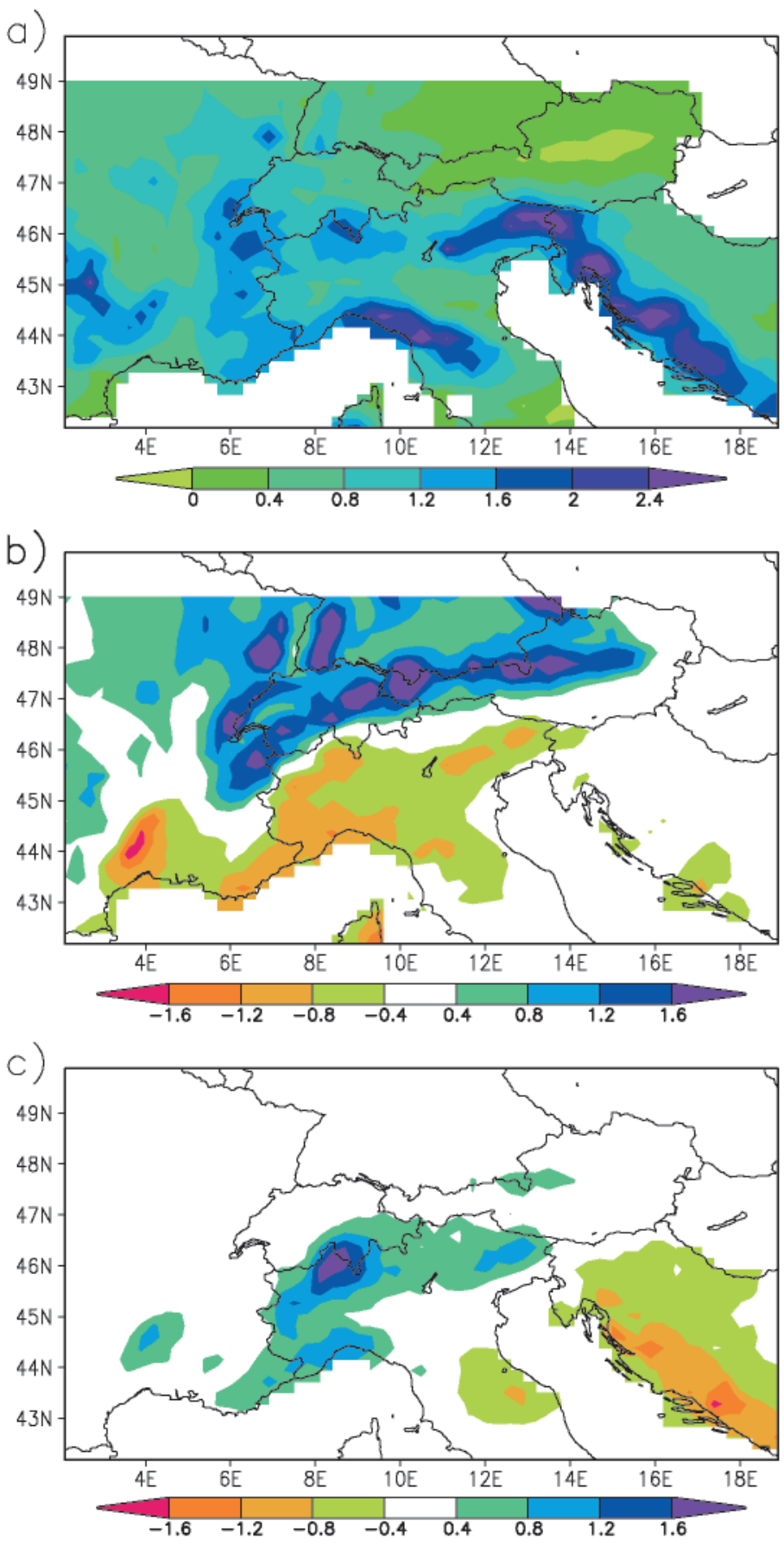

Fig. 3. The 3 leading EOFs of winter precipitation anomalies $\left(\mathrm{mm} \mathrm{d}^{-1}\right)$
Table 1. Correlation coefficients between spatial patterns of EOFs of respective order for different samples. H1: 1971-1981; H2: 1982-1992; TOT: 1971-1992; DET: 1971-1992 de-trended data set

\begin{tabular}{|ccccc|}
\hline & H1-TOT & H2-TOT & H1-H2 & TOT-DET \\
\hline EOF1 & 0.98 & 0.80 & 0.75 & 0.99 \\
EOF2 & 0.98 & 0.92 & 0.84 & 0.99 \\
EOF3 & 0.93 & 0.92 & 0.76 & 1.00 \\
\hline
\end{tabular}

greater than $99 \%$ ). The 2 periods have a substantial variation in the fraction of the total variance explained by the 2 leading EOFs. Looking at Table 2, we observe that the variance explained by EOF1 is strongly reduced in the second decade, while the EOF2 variance increases.

The temporal variability relative to these spatial patterns is shown in Fig. 4, which presents the time series (PCs) associated with the 3 leading EOFs. A linear regression analysis was performed to investigate the presence of trends, and the results are shown in Table 3 . The values of the variable Student's $t$ are obtained after prewhitening the seasonally averaged time series of the PCs (von Storch 1995). To this aim, the lagautocorrelation $\alpha$ at lag-1 is estimated for each series $x_{t}$ and the test is conducted on the new time series, $y_{t}=x_{t}-a x_{t-1}$, which is much less affected by serial correlation. In this way we are able to eliminate stochastic fluctuations generated by a first-order autoregressive (AR[1]) process from any signal of trend. The significance level of rejection of the null hypothesis ('no trends') is given in the last row of Table 3.

We observe that the poorly significant $(80 \%)$ negative trend shown by PC1 over the whole period becomes significant at the 99\% level for 1977-1992. PC2 is instead characterized by a weak positive trend over all the period (significant at the $87 \%$ level). Considering these features and recalling that the first 2 EOFs explain most of the variance of the field, it can be concluded that the winter precipitation has decreased over the southern sector of the region
The robustness of this EOF decomposition was tested by repeating the analysis separately over the 2 half periods of the data set used (H1: 1971-1981; H2: 1982-1992), again for the winter months alone. The resulting structures are very similar to the previous ones, as seen in Table 1, where the correlation coefficients between the spatial patterns corresponding to the whole period and to the two $11 \mathrm{yr}$ sub-periods are shown (the significance level for all the coefficients is
Table 2. Percentages of variance explained by the leading 3 EOFs for different samples. See Table 1 for sample definitions

\begin{tabular}{|lrrrr|}
\hline & TOT & H1 & H2 & DET \\
\hline EOF1 & 38.6 & 43.6 & 35.3 & 39.4 \\
EOF2 & 21.3 & 18.9 & 24.1 & 19.2 \\
EOF3 & 7.8 & 7.7 & 8.5 & 8.2 \\
Total & 67.7 & 70.2 & 67.9 & 66.8 \\
\hline
\end{tabular}



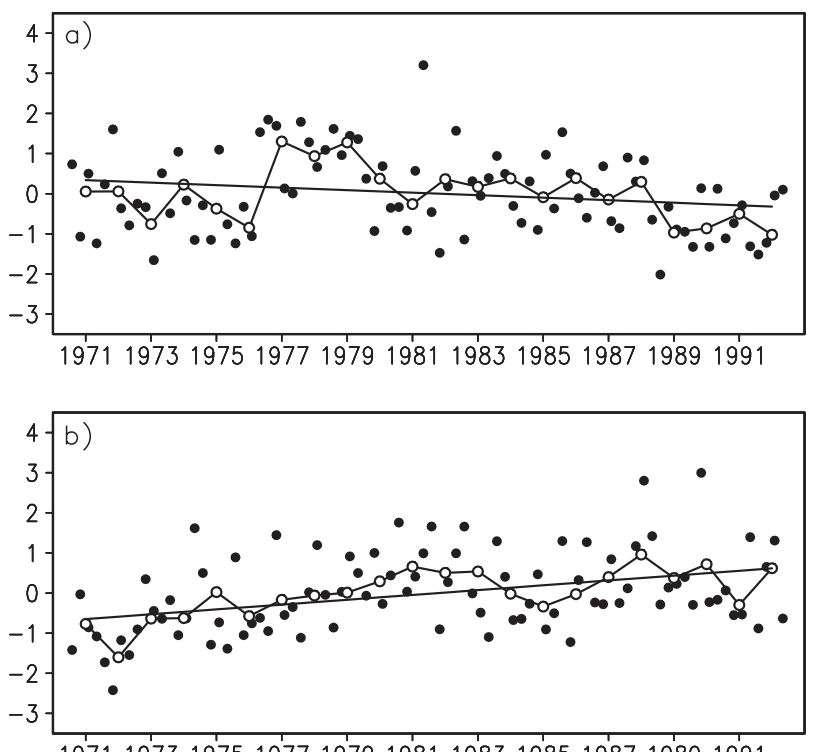

19711973197519771979198119831985198719891991

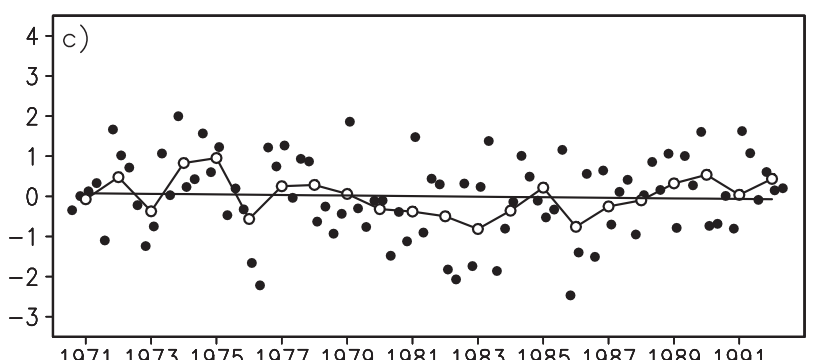

Fig. 4. Time series of the standardized precipitation PCs: winter monthly values (DJFM, solid circles), seasonal averages (open circles connected by a solid line) and regression lines

(Massif Central, northern Italy and the Croatian coast) and slightly increased north of the Alpine chain. This is consistent with the map (shown in Fig. 5) of winter observed trends computed by means of least-squares esti-
Table 3. Trend analysis of the 3 leading precipitation PCs, after pre-whitening the seasonally averaged time series for 1971-1992: Student's $t$ values and significance level of null hypothesis rejection. $\mathrm{PC}^{*}$ : only 1977-1992

\begin{tabular}{|lcccc|}
\hline & PC1 & PC1 ${ }^{*}$ & PC2 & PC3 \\
\hline$t$ & -1.32 & -3.71 & 1.58 & -0.4 \\
$\%$ & 80 & 99 & 87 & 31 \\
\hline
\end{tabular}

mates for each individual grid point time series. The significance levels shown in Fig. 5 have been computed after pre-whitening the seasonal averaged time series, as before for the individual PCs. The result is a dipolar pattern over the entire domain, with 2 contrasting regions located north and south of the Alpine chain, which move toward wetter and drier conditions, respectively, during the winter season of the period. The maximum observed values are $+1 \mathrm{~mm} \mathrm{~d}^{-1}$ decade $^{-1}$ for the positive trend and $-2.5 \mathrm{~mm} \mathrm{~d}^{-1}$ decade $^{-1}$ for the negative trend, and the significance level is generally higher for the grid-points characterized by decreasing precipitation. In particular the areas of strongest significance (greater than 99\%) are located over western Italy, the southern French coast and the Massif Central, but a larger region including most of the Po Valley shows a significance always greater than $95 \%$.

This result is consistent with other studies, which focus on regions partially overlapping the one analyzed here, but for longer time series. For example, Widmann \& Schär (1997) detected significant positive trends of winter precipitation over some sub-regions in Switzerland for 1961-1990 and for a longer period (1901-1990). For the period 1961-1990 they found trends between 0.3 and $0.9 \mathrm{~mm} \mathrm{~d}^{-1}$ decade $^{-1}$, in agreement with our mean value of $0.5 \mathrm{~mm} \mathrm{~d}^{-1}$ decade $^{-1}$. For the same years, Schönwiese et al. (1994) detected an increasing trend in winter Alpine precipitation (25 to
Fig. 5. Grid-point winter precipitation trends (isolines, $\mathrm{mm} \mathrm{d}^{-1}$ decade $^{-1}$ ) and values of the 2 -tailed Student's $t$-test after prewhitening the seasonal averages (shaded contours). Significance levels of null hypothesis rejection for decreasing absolute $t$ values: 99,98 $95,90,80$ and $70 \%$

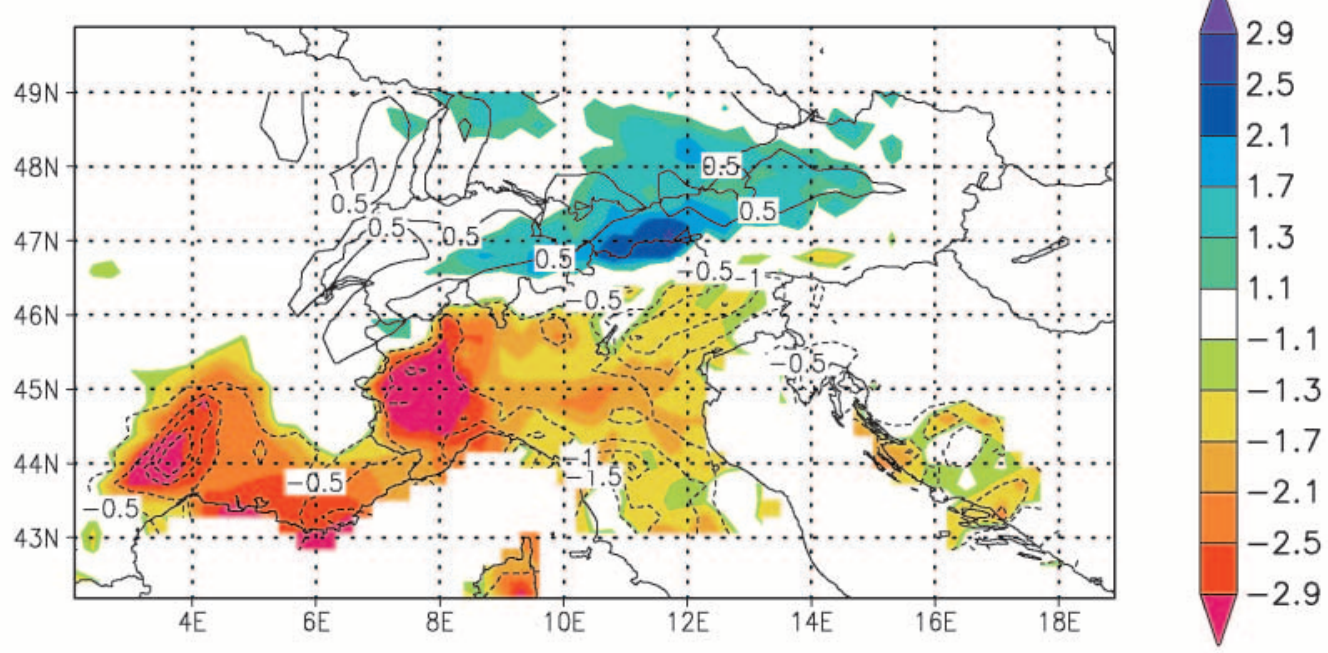


$30 \mathrm{~mm}$ in $30 \mathrm{yr}$ on average over the area) and a less significant decrease over the area south of the Alps. A negative winter trend was also found for the shorter period 1979-1995 over the whole Mediterranean basin (Quadrelli et al. 2001). It should be noted that both the magnitude and the spatial structure of trends are very sensitive to the length of the time series, the selected years and the data set resolution. For example, in our case the choice of the period deeply influences the magnitude of the negative trends in the southern part of the region. The same linear regression performed on the 2 halves of the data set reveals stronger negative trends in the second sub-period. Furthermore, other authors, studying data from 30 stations in northern Italy, show that the period 1980-1999 is characterized by a strong precipitation decrease which was not detected in the previous 20 yr (Buffoni et al. 1999, Zuccherelli 2000).

Comparing Figs $3 \& 5$, we observe that the spatial pattern exhibited by the observed trend is similar to the the second EOF (the correlation coefficient between the 2 maps is $r=0.91$ ). However, the EOF decomposition leads to the same patterns even when repeated over a de-trended data set, obtained by subtracting from each individual grid point time series its corresponding linear regression estimate. This similarity is confirmed by the very high correlation coefficients between these de-trended EOFs and the original ones (see Table 1). Even the proportion of the explained variance of the de-trended set EOFs is similar to that of the original data set. We can conclude that the EOF-derived spatial structures are real variability patterns and not the mere product of a linear trend in the data. Even if the period is not long enough to enable the detection of a strongly significant climatic change, it is likely that the observed long-term variation of precipitation distribution is not due to different variability patterns, but to a modified frequency of occurrence of the same patterns.

\section{LINKS BETWEEN PRECIPITATION AND LARGER SCALE CIRCULATION ANOMALIES}

The relationship between surface regional data and upper air large-scale fields was investigated using the covariance maps of the Alpine precipitation PCs with both the hemispheric Z500 anomalies and the blocking frequency time series.

\subsection{0 hPa geopotential height}

Fig. 6 presents the covariance maps between the Z500 monthly anomalies (for the Northern Hemi-
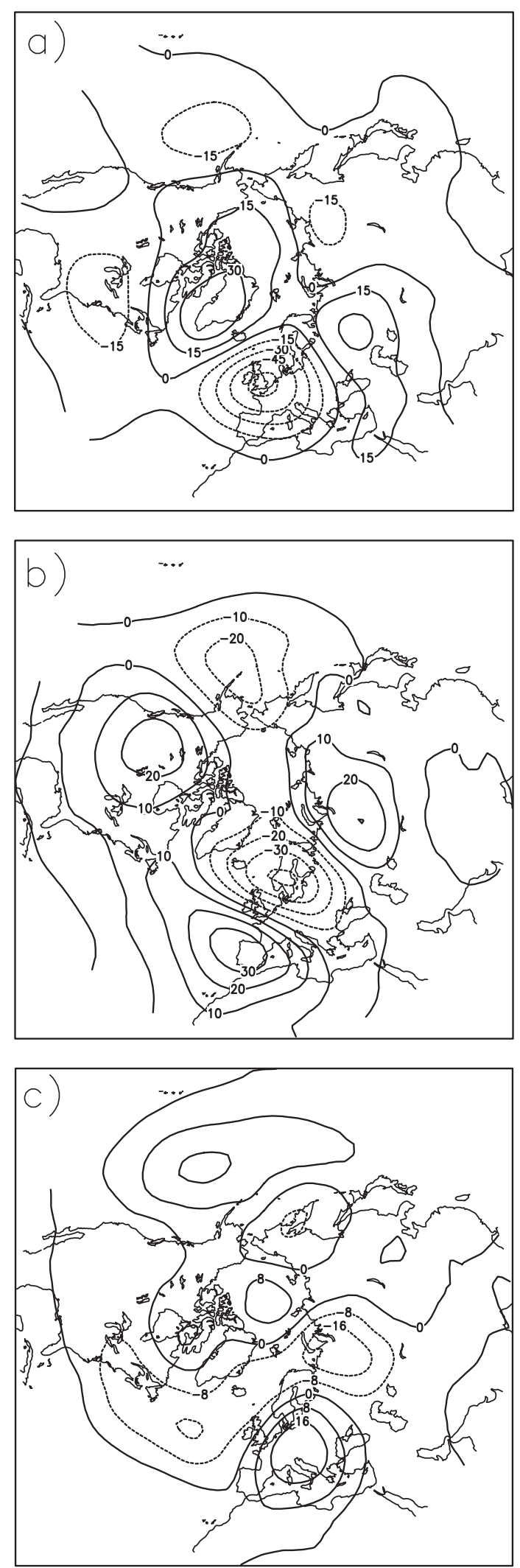

Fig. 6. Covariance maps between Z500 monthly anomalies and the 3 leading precipitation PCs (m) 
sphere, from $20^{\circ} \mathrm{N}$ to the North Pole) and the 3 leading precipitation PCs. The common feature of all these geopotential maps is their large-scale spatial structure. The first pattern is characterized by a strong latitudinal gradient between Greenland and western Europe, describing a north-south fluctuation of the mid-latitude westerlies. This structure resembles the upper level NAO, the pattern which dominates the low-frequency variability of the Atlantic and Europe (for a definition of NAO based on Z500, see, for example, Barnston \& Livezey 1987). This result is confirmed by the computation of the covariance between the first Alpine PC and global precipitation anomalies (data set from Xie \& Arkin 1997), which enables the signal to be extended outside the Alpine region. The resulting pattern, shown over the whole of Europe in Fig. 7, closely resembles the dominant European pattern of precipitation variability (see Quadrelli et al. 2001, Graf \& Perlwitz 1998) associated with the NAO and, more generally, with the Arctic Oscillation (Thompson \& Wallace 1998). This suggests that the centres of action which dominate the Alpine winter precipitation variability are the same as those governing larger-scale patterns. Specifically, a positive pressure anomaly in the northern European region and a negative one in the southern region (negative NAO phase) cause a precipitation shift towards southern Europe, including the whole Alpine region. The reversed phase (positive NAO) leads to more intense precipitation over northern Europe and drier conditions in southern Europe, in agreement with Hurrell (1995). The correlation of the first Alpine precipitation PC with the NAO index, shown in Tables $4 \& 5$, is negative and very large $(r=-0.73$; $r=-0.71$ for de-trended time series).

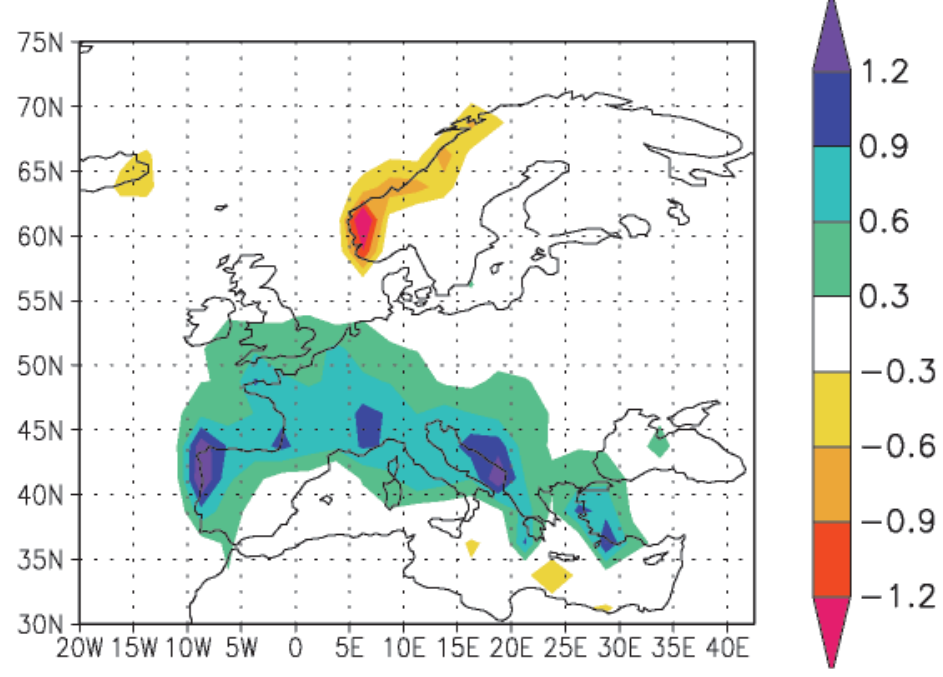

Fig. 7. Covariance map of the first Alpine PC with winter precipitation anomalies over Europe (data set from Xie \& Arkin 1997, mm d$^{-1}$ )
Table 4. Correlation coefficients between seasonally averaged values of the 3 leading winter Alpine precipitation PCs and large-scale pattern indices for the 22 yr period 1971-1992

\begin{tabular}{|lrrr|}
\hline & PC1 & PC2 & PC3 \\
\hline NAO & -0.73 & 0.12 & 0.01 \\
BL-ATL & 0.68 & 0.08 & -0.11 \\
BL-EUR & -0.22 & -0.66 & -0.01 \\
PNA & 0.10 & 0.34 & -0.34 \\
NINO3 & 0.09 & 0.44 & -0.32 \\
\hline
\end{tabular}

The Z500 pattern associated with the second Alpine precipitation EOF is characterized by 2 main opposite centres of action over Europe. When the positive (negative) centre is located over the Iberian Peninsula and the negative (positive) centre over Scandinavia, a north-westerly (south-easterly) anomalous flow impinges on the Alpine chain producing drier (wetter) weather in the southern Alpine region and wetter (drier) conditions over the other side of the chain. Tables $4 \& 5$ show that PC2 is negatively correlated with the European blocking index $(\mathrm{r}=-0.66 ; \mathrm{r}=-0.71$ for de-trended time series $)$, in agreement with the strong blocking signature over Europe in Fig. 6b. The weak correlation of the same PC2 with the 'Niño 3 ' index $(r=0.44$, Table 4) does not appear significant when correlating the de-trended time series (Table 5), showing that PC2 does not follow the interannual variability of the El Niño/Southern Oscillation (ENSO). This result does not contradict the assessment that there is an impact of El Niño on Europe, but it is found to be smaller than the magnitude of internal variability (Fraedrich 1994).

The covariance map associated with PC3 (Fig. 6c) is characterized by much weaker signals than those of the previous $2 \mathrm{PCs}$, in agreement with the absence of significant correlations with large-scale patterns (Tables 4 \& 5).

Table 5. Correlation coefficients between seasonally averaged values of the 3 leading Alpine precipitation PCs and large-scale pattern indices for the 22 winters 1971-1992 computed after subtracting the linear trend from each time series. ${ }^{* *} 99 \%$ significance level

\begin{tabular}{|lccr|}
\hline & PC1 & PC2 & PC3 \\
\hline NAO & $-0.71^{* *}$ & -0.05 & 0.03 \\
BL-ATL & $0.67^{* *}$ & 0.31 & -0.14 \\
BL-EUR & -0.32 & $-0.71^{* *}$ & -0.03 \\
PNA & 0.20 & 0.23 & -0.33 \\
NINO3 & 0.21 & 0.32 & -0.31 \\
\hline
\end{tabular}




\subsection{Blocking frequency}

We also investigated the relationship between precipitation and upper-air circulation anomalies using the Tibaldi \& Molteni (1990) blocking frequency. The blocking pattern has been widely described in the recent literature (e.g. Tibaldi et al. 1994, Pavan et al. 2000). Its climatological frequency is characterized by 2 peaks over the Euro-Atlantic and the Pacific sectors. As seen in Tables 4 \& 5, the first and second EOFs are highly correlated with the blocking frequency anomalies localized over 2 sub-regions of the Euro-Atlantic sector, around $60^{\circ} \mathrm{W}$ and $0^{\circ}$. This is consistent with Fig. 8, which shows the winter climatology of the blocking frequency computed for the months December-March 1971-1992 (Fig. 8a) and the covariance maps of the same field with each of the 3 precipitation PCs (Fig. 8b-d). Each covariance map describes the typical blocking frequency anomaly associated with 1 positive standard deviation of the given PC.

Intense precipitation over almost the entire area, associated with strong EOF1 events, is related to positive blocking frequency anomalies over the west Atlantic (around $60^{\circ} \mathrm{W}$ ), when the NAO is in its negative phase (Fig. 8b). The correlation coefficient between PC1 and the Atlantic blocking index (mean blocking frequency in the band $80-20^{\circ} \mathrm{W}$ ) is, in fact, highly positive $(r=0.68 ; \mathrm{r}=0.67$ for de-trended time series; Tables 4 \& 5) and the indices of NAO and Atlantic blocking are strongly anti-correlated $(\mathrm{r}=-0.84$ for de-trended time series; Table 6). This can be explained by the fact that the Atlantic blocking produces a southward shift of the jet-stream and, as a consequence, a southward moisture transport towards the Mediterranean basin instead of northern Europe. In Fig. 8b we observe that the covariance peak around $60^{\circ} \mathrm{W}$ associated with positive EOF1 precipitation anomalies represents a $40 \%$ increase in blocking events with respect to climatological values. The negative covariance peak centered around $0^{\circ}$ does not have the same relevance, since it explains only a $10 \%$ decrease for this longitude of high variability.

Table 6. Correlation coefficients between seasonally averaged values of large-scale pattern indices for the 22 winter period 1971-1992 computed after subtracting the linear trend from each time series. ${ }^{* *} 99 \%$ significance level; ${ }^{*} 98 \%$ significance level

\begin{tabular}{|lcccrr|}
\hline & NAO & BL-ATL & BL-EUR & PNA & NIÑO3 \\
\hline NAO & \multirow{2}{*}{1.00} & $-0.84^{* *}$ & 0.10 & -0.03 & -0.07 \\
BL-ATL & & 1.00 & -0.33 & 0.03 & 0.17 \\
BL-EUR & & & 1.00 & -0.14 & -0.07 \\
PNA & & & & 1.00 & $0.52^{*}$ \\
NIÑO3 & & & & & 1.00 \\
\hline
\end{tabular}
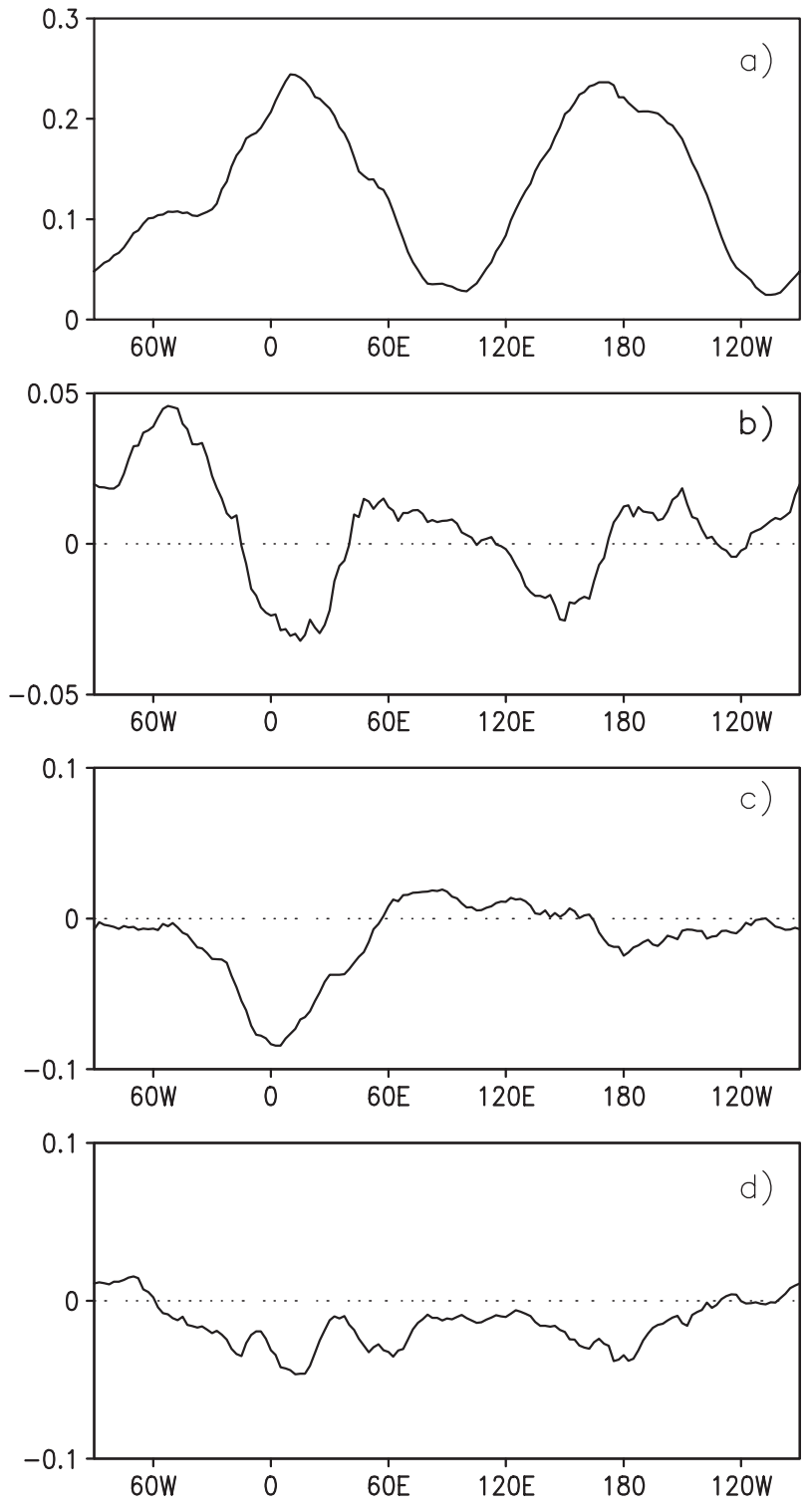

Fig. 8. Blocking frequency: (a) winter climatology; (b-d) covariance with the leading 3 precipitation PCs

A strong blocking frequency signal is also detected in association with the second precipitation PC (Fig. 8c), as mentioned above. In agreement with the highly significant anti-correlation $(\mathrm{r}=-0.66 ; \mathrm{r}=-0.71$ for detrended time series; Tables 4 \& 5) between PC2 and the European blocking index (mean blocking frequency in the band $20^{\circ} \mathrm{W}$ to $40^{\circ} \mathrm{E}$ ), an increase in blocking episodes over the eastern Atlantic and western Europe $\left(+40 \%\right.$ compared to climatology around $\left.0^{\circ}\right)$ is associated with negative EOF2 precipitation anomalies, with dry conditions over the northern Alpine side and wet anomalies over the southern side.

A lower level of significance is observed in the case of the covariance for EOF3, which does not localize the 
blocking frequency signal over any particular longitude (Fig. 8d).Recalling the discussion of Section 3, we observe that the high correlation coefficients between PC1 and NAO and between PC2 and European blocking are not affected by any trend present in this short period of record. As shown in Table 5, the significance of both these 2 correlations is $99 \%$, based on detrended time series.

\section{SUMMARY AND CONCLUSIONS}

The Alpine region is very complex and its weather is determined by many topographical factors, such as orography, a maritime influence, or its location between the mid-latitude temperate zone and the Mediterranean area.

Using the Frei \& Schär (1998) precipitation data set, we performed a PCA to describe the spatial and temporal precipitation variability over this region for the 1971-1992 winters. The area covered by the data includes northern Italy, south-eastern France, Switzerland, Austria, Slovenia and northern Croatia.

To understand how local variability is related to larger-scale circulation anomalies, covariance maps of the PCs were computed both with Z500 geopotential height and blocking frequency. We showed that the winter precipitation variability over the Alpine region is determined by low-frequency fluctuations affecting the whole of Europe. Most of the precipitation variance is explained by the NAO, and the consequent northsouth shift of the Atlantic storm track pattern; overall the Alpine region tends to be drier during months of positive NAO phase.

Blocking is also relevant for the location of precipitation anomalies over the Alpine area. The occurrence of West-Atlantic blocking (mostly when the NAO phase is negative) implies an increase in the precipitation over the whole Alpine area. In fact, the splitting of the jets caused by a blocking episode allows the southern branch of the westerlies to reach southern Europe. Furthermore, European blocking determines different precipitation patterns over the northern and southern sides of the Alpine chain. The high-pressure anomaly at high latitudes causes dry conditions over the whole of the northern side, while the southern anomalies are positive.

The robustness of the relationship between the Alpine precipitation variability and its associated circulation anomalies is validated by the fact that results obtained by other authors are similar. For example, Burkhardt (1995), who analyzed station data for the 1951-1984 winter months, obtained precipitationgeopotential coupled patterns which closely resemble ours (Figs 1 \& 5, patterns 1 and 2), showing that these structures are also detectable for a longer period than the one we examined.

We have discussed the weak relation between the observed Alpine precipitation and the Pacific variability due to El Niño; we highlight the fact that our data set is too short to assess the significance of such a small signal.

The observed temporal variations of precipitation are also a very interesting subject of analysis, in the context of the general debate on anthropogenic climatic change (Houghton et al. 1990) and its regionalscale implications. Significant trends were detected for the winter season over some areas within the Alpine region. Specifically, the sector north of the Alpine chain exhibits an increase in observed winter precipitation, in agreement with more spatially localized results obtained by other authors studying longer periods (Schönwiese et al. 1994, Widmann \& Schär 1997). On the other hand, south of the Alps, the trend is opposite and stronger, with precipitation decreasing up to $2.5 \mathrm{~mm} \mathrm{~d}^{-1}$ decade $^{-1}$ over the most affected points (Massif Central and western Italy). This dipolar feature could be seen as the superposition of a weak negative trend for the whole area (PC1) and a north-south dipolar trend (PC2) which tends to strengthen the decrease in precipitation only in the southern part of the region, where in fact we find the most highly significant values of the grid-point trends.

The EOF decomposition repeated over a de-trended data set led to the same spatial patterns. Our data set covers a period too short to reach definitive conclusions, but our results seem to support the hypothesis that a possible climatic change does not modify the variability patterns of precipitation, but only varies their intensity or their frequency of occurrence.

Acknowledgements. The work described in this paper has been carried out as part of the ACCORD project (contract no. ENV4-CT97-0530), supported by the European Union. The Alpine precipitation analyses, version V.4 (Frei \& Schär 1998), data set was retrieved from the MAP data centre. NCEP reanalyses were retrieved from the NCEP data center.

\section{LITERATURE CITED}

Barnston AG, Livezey RE (1987) Classification, seasonality and persistence of low-frequency atmospheric circulation patterns. Mon Weather Rev 115:1083-1126

Bretherton CS, Smith C, Wallace JM (1992) An intercomparison of methods for finding coupled patterns in climate data. J Clim 5:1083-1126

Buffoni L, Maugeri M, Nanni T (1999) Precipitation in Italy from 1833 to 1996. Theor Appl Climatol 63:33-40

Burkhardt U (1995) How well do climate models perform on a small scale? Clim Dyn 11:299-305

Buzzi A, Tibaldi S (1978) Cyclogenesis in the lee of the Alps: a case study. Q J R Meteorol Soc 104:271-287 
Cacciamani C, Tibaldi S, Nanni S (1994) Mesoclimatology of winter temperature and precipitation in the Alpine Region of Northern Italy. Int J Climatol 14:777-814

Cacciamani C, Battaglia F, Patruno P, Pomi L, Selvini A, Tibaldi S (1995) A climatological study of thunderstorm activity in the Po Valley. Theor Appl Climatol 50:185-203

Fliri F (1975) Synoptische Klimatographie der Alpen zwischen Mont Blanc und Hohen Tauern. Wissenschaftliche Alpenvereinshefte, 29, Innsbruck

Fraedrich K (1994) An ENSO impact on Europe? A review. Tellus 46A:541-552

Frei C, Schär C (1998) A precipitation climatology of the Alps from high-resolution rain-gauge observations. Int $\mathrm{J}$ Climatol 18:873-900

Giorgi F, Mearns LO (1991) Approaches to the simulation of regional climate change. A review. Rev Geophys 29: 191-216

Graf HF, Perlwitz J (1998) Secular variability of the North Atlantic Oscillation. Abstract book of the second European conference on applied climatology, October 1998. ECAC, Vienna, p 24

Houghton JT, Jenkins GJ, Ephramus JJ (1990) Climate change. The IPCC scientific assessment. Cambridge University Press, Cambridge

Houze RA (1993) Cloud dynamics. Academic Press, Inc, San Diego

Hurrell JW (1995) Decadal trends in the North Atlantic Oscillation: regional temperatures and precipitation. Science 269:676-679

Kalnay E, Kanamitsu M, Kistler R, Collins W, Deaven D, Gandin L, Iredell M, Saha S, White G, Woollen J, Zhu Y, Chelliah M, Ebisuzaki W, Higgins W, Mo KC, Ropelewski C, Wang J, Leetmaa A, Reynolds R (1996) The NCEP/ NCAR 40-year reanalysis project. Bull Am Meteorol Soc 77:437-471

Overland J, Preisendorfer R (1982) A significance test for principal components applied to a cyclone climatology. Mon Weather Rev 110:1-4

Parker DE, Folland CK, Bevan A, Ward MN, Jackson M, Maskell K (1995) Marine surface data for analysis of climate fluctuations on interannual to century time-scales. In: Marthinson DG, Bryan K, Ghil M, Hall MM, Karl TR, Sarachick ES, Sorooshian S, Talley LD (eds) Natural climate variability on decade-to-century timescales. National Research Council, National Academy Press, Washington, DC, p 241-250

Pavan V, Tibaldi S, Brancovic C (2000) Seasonal prediction of blocking frequency: results from winter ensemble experiments. Q J R Meteorol Soc 126:2125-2143

Quadrelli R, Pavan V, Molteni F (2001) Wintertime Mediter- ranean precipitation patterns and their links with largescale circulation anomalies. Clim Dyn 7(5/6):457-466

Schär C, Davies TD, Frei C, Wanner H, Widmann M, Wild M, Davies HC (1998) Current Alpine climate. In: Cebon P, Dahinden U, Davies HC, Imboden DM, Jager C (eds) Views from the Alps: regional perspectives on climate change. MIT Press, Boston, p 21-72

Schönwiese CD, Rapp J, Fuchs T, Dehnard M (1994) Observed climate trends in Europe 1891-1990. Meteorol Z N F $3: 22-28$

Thompson DWJ, Wallace JM (1998) The Arctic Oscillation signature in the wintertime geopotential height and temperature fields. Geophys Res Lett 25(9):1297-1300

Tibaldi S, Molteni F (1990) On the operational predictability of blocking. Tellus 42A:343-365

Tibaldi S, Buzzi A, Speranza A (1990) Orographic cyclogenesis. In: Newton C (ed) Palmen Memorial Volume. American Meteorological Society Monograph, Providence, p $107-127$

Tibaldi S, Tosi E, Navarra A, Pedulli L (1994) Northern and Southern Hemisphere seasonal variability of blocking frequency and predictability. Mon Weather Rev 122:197-200

von Storch H (1995) Misuses of statistical analysis in climate research. In: von Storch H, Navarra A (eds) Analysis of climate variability applications of statistical techniques. Springer-Verlag, Heidelberg, p 11-26

Wallace JM, Gutzler DS (1981) Teleconnections in the geopotential height field during the Northern Hemisphere winter. Mon Weather Rev 109:784-812

Wallace JM, Smith C, Bretherton CS (1992) Singular value decomposition of wintertime sea surface temperature and 500-mb height anomalies. J Clim 5:561-576

Widmann M (1996) Mesoscale variability and long-term trends of Alpine precipitation and its relation to the synopticscale flow. PhD thesis no. 11769, Eidgenössische Technishe Hochshule (ETH), Zurich

Widmann M (1996) Mesoscale variability and long-term trends of Alpine precipitation and its relation to the synoptic-scale flow. PhD thesis no. 11769, Eidgenössische Technishe Hochshule (ETH), Zürich

Widmann M, Schär C (1997) A principal component and longterm analysis of daily precipitation in Switzerland. Int $\mathrm{J}$ Climatol 17:1333-1356

Xie P, Arkin PA (1997) Global precipitation: A 17-year monthly analysis based on gauge observations, satellite estimates and numerical model outputs. Bull Am Meteorol Soc 78: $2539-2558$

Zuccherelli A (2000) Analisi climatica dei dati di temperatura e precipitazione del Nord Italia. Degree thesis, Dept of Physics, University of Bologna

Proofs received from author(s): July 7, 2001 